\title{
Multiple Jejunoileal Atresia and Stenosis with Duplication Cyst in a Newborn
}

\author{
Aditya Pratap Singh ${ }^{1 *}$, Rajlaxmi Pardeshi ${ }^{2}$, Ramesh Tanger ${ }^{1}$, Maryem Ansari ${ }^{3}$, Arun Kumar Gupta ${ }^{1}$ \\ 1 Department of Paediatric Surgery, SMS Medical College Jaipur, Rajasthan, India. \\ 2. Department of Obstetrics and Gynaecology, SMS Medical College Jaipur, Rajasthan, India. \\ 3. Department of Pathology, SMS Medical College Jaipur, Rajasthan, India.
}

\section{ABSTRACT}

Jejunoileal atresia is a congenital anomaly that is characterized clinically by bilious vomiting and abdominal distension. It has been associated with various other anomalies but its association with mesenteric cyst is rare. We are presenting a patient with antenatally diagnosed duplication cyst with multiple jejunoileal atresia and stenosis with possible etiology behind such an association.

\section{Key words: Newborn; Duplication cyst; Jejuno-ileal atresia; Jejunal stenosis}

Correspondence: Dr. Aditya Pratap Singh, Assistant Professor, Department of Pediatric Surgery, SMS Medical College Jaipur, Rajasthan, India.

E-mail: dr.adisms@gmail.com

Submitted: 03-07-2018

Conflict of Interest: None
(C) 2018, Singh et al.

Accepted: 27-08-2018

Source of Support: Nil

This is an open-access article distributed under the terms of the Creative Commons Attribution License, which permits unrestricted use, distribution, and reproduction in any medium, provided the original work is properly cited.

\section{INTRODUCTION}

Jejunoileal atresia (JIA) is a common cause of intestinal obstruction in neonates, with an incidence of about 1 in 5000 live births.[1] Bilious vomiting is always of concern because of its association with surgical etiology. Smith considered bilious vomiting in conjunction with abdominal pain to be a surgical problem unless proved otherwise. [1]

In neonatal period this vomiting is due to high small bowel obstruction which could be due to small bowel atresia, stenosis or malrotation.[2] We present a patient of multiple jejunoileal atresia and stenosis that was associated with a duplication cyst, a rare association

\section{CASE REPORT}

A 24-hour old newborn male baby with 2-kg weight, presented in the emergency department, with antenatal diagnosis of polyhydramnios. Baby was born at term with normal vaginal delivery. Parents were aware about the diagnosis because third trimester ultrasound detected polyhydramnios.

At second trimester fetal ultrasound was reported as normal. Baby had complaint of bilious vomiting. On examination abdomen was not distended and a mobile lump was palpable. Abdominal $x$-ray in erect posture revealed dilated bowel loops with multiple air-fluid levels in upper abdomen and paucity of the gas distally (Figure-1a).Contrast enhanced computed tomography (CECT) showed a large cyst in the right subhepatic region extending to right iliac region, measuring approximately $4 \mathrm{~cm} \times 4.5 \mathrm{~cm}$ displacing bowel loops with soft tissue density at umbilicus (Figure-2b).

Intramuscular collection was seen in pelvis extending to gluteal region and around left hip joint. Small bowel loops were mildly dilated and fluid filled.. 


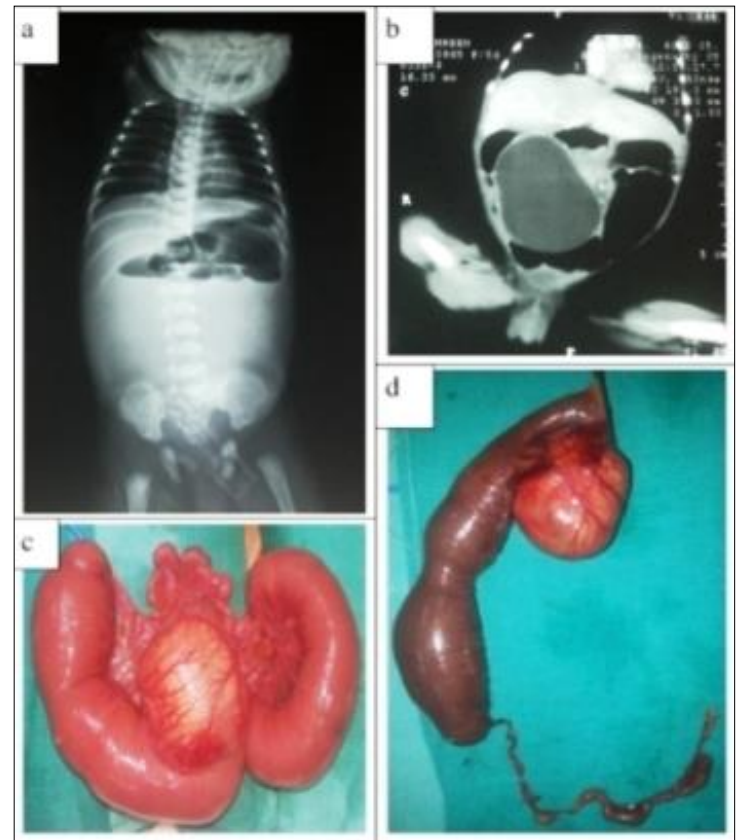

Figure 1: (a) X-ray abdomen erect, (b) CECT images, (c \& d) Peroperative photo showing dilated proximal jejunum with type 1 jejuno-ileal stenosis and proximal duplication cyst compressing a part of the adjoining jejunal segment.

On exploratory laparotomy, multiple jejuno-ileal atresia type 2 (ends were connected with a band without mesenteric defect) at the proximal ileum and distal jejunum with cyst at the proximal part of jejunal mesentery measuring around $4 \mathrm{~cm} \times 4 \mathrm{~cm}$ without any volvulus (Figure 1c \& 1d) found. The cyst was compressing the proximal jejunum for about $3 \mathrm{~cm}$ and could not be separated from it (Figure 1c \& 1d). End-to-back jejuno-ileal anastomosis following resection of the atretic jejunum and ileum along with the dilated jejunal segment and the cyst, was performed.
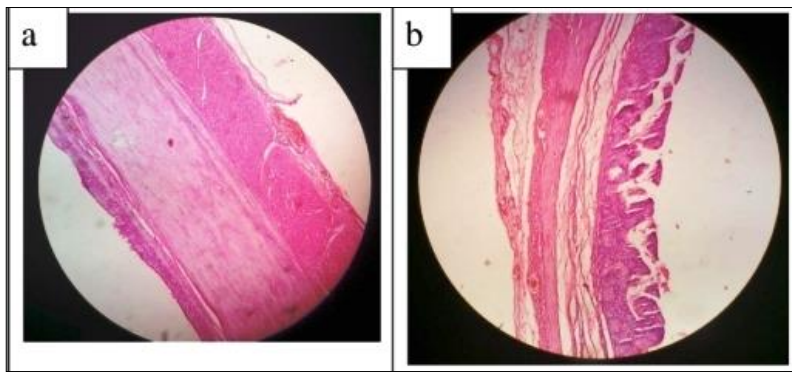

Figure 2: Histopathology image (a) Duplication cyst-normal intestinal mucosa with duplicated muscle layer, (b) Stenosis segment showing hypoplastic muscle layer.

End-to-back jejuno-ileal anastomosis following resection of the atretic jejunum and ileum along with the dilated jejunal segment and the cyst, was performed. The extent of resection was from distal jejunum to proximal ileum. Histopathology report showed multiple jejuno- ileal atresia and stenosis with duplication cyst (Figure $2 a \& 2 b$ ). The postoperative period was stormy and baby expired after 5 days due to sepsis.

\section{DISCUSSION}

Jejunal atresia has been associated with a number of other congenital malformations such as cystic fibrosis, malrotation, congenital heart disease, Down's syndrome, congenital dislocation of hips, anorectal and vertebral anomalies, neural tube defects and microcephaly. It can also coexist with other anomalies like biliary atresia, duodenal atresia, colonic atresia, gastric atresia and Hirschsprung's disease.[3,4,5] The association of mesenteric cyst with JIA is extremely rare.[6] In our patient there were multiple jejuno-ileal atresia and stenosis with duplication cyst without abdominal distension because he presented early in the course of the disease. The anomaly may be associated with maternal polyhydramnios which was also present in our patient.[7] As it was not found on ultrasound in second trimester therefore it is assumed that vascular insult might occurred in the third trimester of gestation.

Intrauterine mesenteric vascular disruptions to a segment of developed intestine may result in JIA.[8] Intestinal atresias secondary to late intrauterine mesenteric vascular insults are often seen in patients with volvulus, intussusceptions, internal hernia, and tight anterior abdominal wall defects. $[4,8]$ Duplication cyst in our patient caused secondary bowel volvulus and it may be the causative factor for the vascular compromise leading to jejuno-ileal atresia and stenosis.[9].

Consent: Authors declared that they have taken informed written consent, for publication of this report along with clinical photographs/material, from the legal guardian of the patient with an understanding that every effort will be made to conceal the identity of the patient however it cannot be guaranteed.

Authors' Contribution: All authors contributed equally in concept, literature review, and drafting of the manuscript and approved the final version of this manuscript.

\section{REFERENCES}

1. Smith SD. Disorders of Intestinal rotation and fixation. In: Pediatric Surgery. Volume 6. 6th edition. Edited by: Grosfeld JL, O'Neill JA Jr, Fonkalsrud EW, Coran AG. Philadelphia: Mosby Elsevier; 2006:1342-58.

2. Myers NA. Vomiting in the first month of life. In: Clinical Pediatric Surgery- Diagnosis and Management. Volume 3. Edited by: Jones PG, Woodward AA. Melbourne: Blackwell scientific publication; 1986:63-72. 
3. Fischer JS, Azizkhan RG. Jejunoileal atresia and stenosis. In: Pediatric Surgery. 7th Edition. Edited by: Arnold G. Coran, Anthony Caldamone, N. Scott Adzick, Thomas M. Krummel, Jean Martin Laberge, Robert Shamberger. Philadelphia: Elsevier; 2012.1059-1071.

4. Sweeney B, Surana R, Puri P. Jejunoileal atresia and associated malformations: correlation with the timing of in utero insult. J Pediatr Surg. 2001;36:774-6.

5. Asabe K, Yukitake K, Mori T, Mitsudome A, Shirakusa T. Biliary atresia associated with jejunal atresia and a review of literature in Japan. Asian J Surg. 2005; 28:154-7.

6. Pandey A, Gangopadhayay AN, Sharma SP, Upadhyaya VD, Kumar V. Jejunal atresia presenting with mesenteric cyst in neonate: a case report. Cases J. 2008,1:57.
7. Grosfeld JA: Jejunoileal atresia and stenosis. Pediatric Surgery. Edited by: Grosfeld JL, O'Neill JA Jr, Fonkalsrud EW, Coran AG. 2006, Mosby Elsevier, Philadelphia, 126988. 6

8. Komuro H, Amagai T, Hori T, Hirai M, Matoba K, Watanabe $\mathrm{M}$, et al. Placental vascular compromise in jejunoileal atresia. J Pediatr Surg. 2004; 39:1701-5.

9. Piplani R, Acharya SK, Sugandhi N, Bagga D. Mesenteric cyst in association with type-II jejunoileal atresia. J Neonat Surg. 2017;6:17. 